Published in final edited form as:

Int Urogynecol J. 2014 August ; 25(8): 1031-1036. doi:10.1007/s00192-013-2308-3.

\title{
Risk factors for lower urinary tract injury at the time of hysterectomy for benign reasons
}

\author{
Mamta M. Mamik ${ }^{1}$, Danielle Antosh ${ }^{2}$, Dena E. White ${ }^{3}$, Erinn M. Myers ${ }^{4}$, Melinda Abernethy ${ }^{5}$, \\ Salma Rahimi ${ }^{1}$, Nina Bhatia ${ }^{5}$, Clifford R. Qualls ${ }^{6}$, Gena Dunivan ${ }^{6}$, and Rebecca G. Rogers ${ }^{6}$ \\ ${ }^{1}$ Icahn School of Medicine at Mount Sinai New York, NY, USA \\ ${ }^{2}$ MedStar Washington Hospital Center, Washington, DC, USA \\ ${ }^{3}$ University of Oklahoma, Oklahoma City, OK, USA \\ ${ }^{4}$ University of North Carolina, Chapel Hill, NC, USA \\ ${ }^{5}$ Institute for Female Pelvic Medicine and Reconstructive Surgery, Allentown, PA, USA \\ ${ }^{6}$ University of New Mexico School of Medicine Albuquerque, New Mexico, USA
}

\section{Abstract}

DISCLOSURES-None of the authors has any conflicts of interest to report except for Dr. Rebecca G. Rogers, who is DSMB chair for American Medical Systems Transform Trial, UptoDate royalties, ACOG royalties, and is on the executive board of the ACOG. Dr. Gena Dunivan is a member of the AUGS Education Committee.

OBJECTIVE-To identify risk factors associated with lower urinary tract injury at the time of performing hysterectomy for benign indications.

METHODS-We conducted a multi-center case-control study of women undergoing hysterectomy for benign disease. Cases were identified via ICD-9 codes for lower urinary tract injury at the time of hysterectomy from 2007 to 2011: controls were two subsequent hysterectomies following the index case in the same institution that did not have lower urinary tract injury. Logistic regression was used to perform univariate and multivariate comparisons between groups.

RESULTS-At 7 centers, 135 cases and 270 controls were identified. Cases comprised 118 bladder injures and 25 ureteral injuries: 8 women had both bladder and ureteral injury. Bladder injury was associated with a history of prior cesarean section OR 2.9 (95\% CI 1.7-5), surgery by a general obstetrician and gynecologist OR 2.4 (95\% CI 1.2-5.2), and total abdominal hysterectomy OR 1.9 (95\% CI 1.06-3.4). Ureteral injury was more likely among women who underwent laparoscopic-assisted vaginal hysterectomy (LAVH) OR 10.4 (95\% CI 2.3-46.6) and total abdominal hysterectomy (TAH) OR 4.7 (95\% CI 1.4-15.6).

CONCLUSION-Bladder injury at the time of benign hysterectomy is associated with a prior history of Cesarean section and TAH as well as surgery by generalist OB-GYN; ureteral injury is associated with LAVH and TAH. 


\section{Keywords}

Bladder injury; Ureter injury; Hysterectomy; Risks

An estimated 600,000 women undergo a hysterectomy each year in the United States [1]. Although rare, lower urinary tract injury is a potentially devastating complication of hysterectomy. Ureteral injury and bladder injury may be associated with increased operating time and significant postoperative morbidity, including possible loss of renal function if unrecognized [2,3]. Gynecological surgery is responsible for up to 64-75\% of cases of iatrogenic injury to the ureter $[4,5]$. The incidence of lower urinary tract injury at the time of hysterectomy ranges from 0.13 to $3.6 \%$ for bladder injury and from 0.1 to $1.8 \%$ for ureteral injury $[2,6-8]$.

Prior studies have suggested that risk factors for lower urinary tract injury at the time of hysterectomy include older age, higher body mass index, longer operating times, increased blood loss, and an increase in uterine size [2,7]. Data regarding risk factors based on the route of hysterectomy are conflicting. Some studies suggest that the risk of bladder injury is highest among laparoscopic-assisted vaginal hysterectomy (LAVH) and total vaginal hysterectomy (TVH) [2,9], while one study reported a higher risk of injury to both the ureters and the bladder with total laparoscopic hysterectomy compared with laparoscopicassisted vaginal hysterectomy [8]. For cases of ureteral injury, some studies report increased risk with the abdominal route [7,9], while another study reported an increased risk with use of the laparoscopic route for hysterectomy [10]. Risk factors for lower urinary tract injuries based on the route or type of hysterectomy performed have been difficult to identify due to the low prevalence rates of injury. The purpose of our study is to determine risk factors for lower urinary tract injury at the time of hysterectomy for benign indications using a multicenter case-control study design.

\section{MATERIALS AND METHODS}

This was a retrospective multi-center case-control study of women undergoing hysterectomy for benign reasons performed at seven clinical sites through the Society of Gynecologic Surgeon's Fellows' Pelvic Research Network (SGS FPRN). All women who underwent a hysterectomy at the respective clinical sites between January 2007 and December 2011 were identified by the appropriate ICD-9 and CPT codes (Table 1). Cases were then identified as any patient with a lower urinary tract injury sustained at the time of hysterectomy and controls were identified as the next two sequential patients undergoing hysterectomy for benign reasons (Table 1). Two controls were identified for each case. Subjects undergoing gynecological, oncological or urogynecological surgery were excluded (Table 1). IRB approval was obtained through each participating institution prior to data collection.

Medical records were reviewed for demographics, estrogen status, smoking history, medical co-morbidities, and surgical history. A Charlson co-morbidity [11] index score (predicts the 10-year mortality for a patient who may have a range of comorbid conditions) was calculated for each subject. Operative outcomes included indication for surgery, route of hysterectomy, concomitant procedures, duration of procedure, uterine weight (grams), blood 
loss, and any intraoperative procedures. Postoperative outcomes of interest included treatment and treatment outcomes for lower urinary tract injury. Bladder and ureteral injuries were analyzed separately.

\section{POWER CALCULATION}

A sample size of 120 cases and 240 controls gave $80 \%$ power at a significance level of 0.05 to find a difference in lower urinary injury between minimally invasive (laparoscopic and vaginal) versus abdominal hysterectomy with an OR of 1.9 for increased lower urinary tract injury with minimally invasive hysterectomy. We based our estimates on a prior study by Frankman et al. [8], which found a similar OR.

\section{STATISTICAL ANALYSIS}

Statistical analyses were performed using SAS v9.2 (SAS Institute, Cary, NC, USA). Summary statistics were calculated for the study population. Demographic information of the two groups was compared using Student's $t$ tests for continuous variables and Pearson's Chi-squared for categorical data. Univariate logistic regression was used to evaluate the association among lower urinary tract injury and completed route of hysterectomy, surgeon type (general gynecologist, gynecological oncologist, or urogynecologist), cystoscopy, and prior abdominopelvic surgery. All covariates found to be significant on univariate analysis were incorporated into a multivariate model. Backward stepwise logistic regression entered these potential covariates as predictors associated with lower urinary tract injury and to evaluate for interaction and confounding within the model. Model fit was confirmed with likelihood ratio and c-statistics. When evaluating for confounding, a difference greater than $15 \%$ between the adjusted and crude odds ratio was considered significant. A two-sided $p$ value of $<0.05$ was considered significant for all analyses.

\section{RESULTS}

At seven centers 135 cases and 270 controls were identified. Cases comprised 110 bladder injuries only, 17 ureteral injuries, and 8 women who had both bladder and ureteral injury. Cases and controls did not differ in age, (mean age $45.2 \pm 7.6$ vs $46.1 \pm 9.5$ years, $p=\mathrm{NS}$ ) or ethnicity/race ( 45 vs $49 \%$ Caucasian, $p=\mathrm{NS}$ ), and body mass index ( $27.9 \pm 11.6$ vs 29.1 $\pm 12.1 \mathrm{~kg} / \mathrm{m} 2, p=\mathrm{NS}$; Table 2 ). The majority of hysterectomies among cases were performed with a minimally invasive approach with 34 vaginal, 40 laparoscopic, and 61 abdominal hysterectomies. On multivariate analysis after controlling for cystoscopy, total abdominal hysterectomy was associated with bladder injury OR 1.9 (95\% CI 1.06-3.4) as well as ureteral injury OR 4.7 (95 \% CI 1.4-15.6). Bladder injury was also associated with a history of prior cesarean section OR 2.9 (95\% CI 1.7-5), and surgery by a general obstetrician and gynecologist OR 2.4 (95\% CI 1.2-5.2; Table 3). Women with bladder injury were more likely to have concurrent bowel injury OR 8.9 (95 \% CI 5.6-17). Ureteral injury was more likely among women who underwent laparoscopic-assisted vaginal hysterectomy (LAVH) OR10.4 (95 \% CI 2.3-46.6), and total abdominal hysterectomy OR 4.7 (95 \% CI 1.4-15.6). Patients with ureteral injuries were more likely to undergo blood transfusion OR 33.4 (95\% CI 7.3-153.2), and similar to those with bladder injuries, women with ureteral injuries have 
increased odds of concurrent bowel injury OR 21.1 (95 \% CI 1.6-167). Among the cases of lower urinary tract injury, total abdominal hysterectomy patients had a mean uterine weight of $840 \mathrm{~g} \pm 1,158 \mathrm{~g}$ and those who had other types of hysterectomy had a mean uterine weight of $244 \mathrm{~g} \pm 210 \mathrm{~g}$ and these differences were statistically significant ( $p<0.0001$ ). The estimated blood loss was also significantly different between these two groups. i.e., TAH $865 \pm 986 \mathrm{ml}$, vs other hysterectomies, $439 \pm 662 \mathrm{ml}$ ( $p<0.0078)$. There were no significant differences between patients undergoing TAH and other hysterectomy as far as body mass index, prior pelvic surgery, and endometriosis were concerned. When these factors were assessed for LAVH, none of the differences between LAVH and other hysterectomies reached significance.

Prior pelvic surgery, menopausal status (pre-/postmenopausal), medical comorbidities, history of pelvic inflammatory disease, history of pelvic malignancy, endometriosis, and chronic pelvic pain were not risk factors or protective against lower urinary tract injury. Likewise, we found that the use of energy sources such as Ligasure ${ }^{\circledR}$, Gyrus ${ }^{\circledR}$, and monopolar and bipolar scissors were not risk factors or protective for either injury type.

\section{DISCUSSION}

In this multi-center case - control study, we found that while the majority of lower urinary tract injury cases were noted at the time of the total abdominal hysterectomy (ureteral and bladder), there were also injuries during the minimally invasive laparoscopic-assisted vaginal hysterectomy (ureteral). With more gynecologists using minimally invasive techniques for hysterectomy, determining the risk factors associated with these surgical routes is of vital importance. A systematic review and meta-analysis [12] on the methods of hysterectomy analyzing 34 randomized controlled trials with 4,495 women included further divisions of hysterectomy like laparoscopic hysterectomy (defined as the ligation of uterine vessels laparoscopically and the remainder of the surgery done vaginally) and total laparoscopic hysterectomy, where the entire procedure was carried out laparoscopically, in addition to abdominal and vaginal hysterectomy. When bladder and ureter injuries were pooled under "urinary tract injury," there was a significant increase in urinary tract injury for laparoscopic hysterectomy versus abdominal hysterectomy. There were no statistically significant differences in bladder, ureter, or vascular injuries between the laparoscopic and vaginal groups either. When specific laparoscopic groups were analyzed, there were more urinary tract injuries for total laparoscopic hysterectomy versus vaginal hysterectomy (OR 3.69; $95 \%$ CI 1.11 to 12.24). There were no statistically significant differences between laparoscopic and vaginal hysterectomy. Another study [8] looking at hysterectomy and lower urinary tract injury from 1979 to 2006, which did not include total or supracervical laparoscopic approaches, found that bladder injury was highest in women undergoing LAVH (13.8 per 1,000 women) and $\mathrm{VH}$ (13.1 per 1,000 women). Ureteral injury recognized at the time of hysterectomy was most common with radical abdominal hysterectomy ( 7.7 per $1,000)$ and total abdominal hysterectomy $(1.2$ per 1,000), similar to our study. Again this study spans two decades, but unfortunately does not have the gamut of laparoscopic approaches, including robotic hysterectomy for comparison, which makes its application to the current gynecological surgical scene inadequate. Based on the recent Cochrane review [12], as well as the study by Jelovsek et al. [8], more recent comparative studies on various 
approaches of hysterectomy and concurrent lower urinary tract injury are lacking to realistically compare the current gynecological surgical scenario. Multiple explanations are possible for the outcomes of our study. Total abdominal hysterectomy re- mains the commonest route of surgery and the prevalence may simply reflect the odds of getting an injury simply because of how frequently this procedure is performed. Furthermore, it is possible that easier cases are scheduled laparoscopically or vaginally rather than as abdominal hysterectomy cases, as indicated by the uterine weight and possibly the estimated blood loss, thus increasing the risk of injury. In addition, the learning curve of laparoscopic surgeries may have passed and we are back to the baseline incidence of lower urinary tract injury rates in the laparoscopic group as far as robotic, total laparoscopic, and laparoscopic supracervical hysterectomy are concerned. It does remain interesting that LAVH is a risk factor for ureteral injury, indicating that perhaps a combined approach is fraught with possible anatomical distortion and consequent injury. Since total abdominal hysterectomy is also a risk factor for ureteral injury, this seems to indicate either again the prevalence of the procedure, or possibly that more complicated cases are being performed abdominally with the advent of laparoscopic surgery, and that the complications occur at a disproportionate rate in the abdominal hysterectomy cases. Further large-scale epidemiological studies need to be per- formed to confirm these findings.

Unlike prior reported data, we did not find an association between patient age, BMI, or menopausal status, and the risk of lower urinary tract injury. However, higher rates of bladder injuries occurred among women who have undergone a prior cesarean section. This is consistent with published data as well as with generalized knowledge regarding the altered anatomy of the vesicovaginal space following prior dissection in this area. Interestingly, we also noted higher rates of bladder injuries when the surgery was performed by a general gynecologist, compared to a subspecialist in the field. While it is difficult to extrapolate further information from this finding, it points to the necessity of appropriate education for all gynecologic surgeons regarding risk-lowering procedural steps during hysterectomy.

Injury to the lower urinary tract at the time of hysterectomy is also associated with other unfortunate sequelae, including higher rates of blood transfusion and concurrent bowel injuries indicating that anatomical complexities and possibly operator experience could predispose an individual to higher risks of injury and increased blood loss.

A recent case analysis of 31 ureteral injuries incurred at the time of laparoscopic hysterectomy was completed in the Netherlands [13]. Researchers asked all 95 gynecologists performing laparoscopic hysterectomy to recall all cases of known ureteral injuries that occurred at their hospital and complete a structured interview focusing on the identification of possible predisposing factors. While severely limited by the recall and associated biases of performing surgeons, the study did acknowledge interesting areas for improvement in the prevention of lower urinary tract injury at the time of minimally invasive hysterectomy. Specifically, the importance of having an experienced surgeon as part of the surgical team (in $25 \%$ of cases, the combined surgical experience of the first surgeon and primary assistant was fewer than 30 laparoscopic hysterectomies), and differences in surgical approach (i.e., standardized use of a uterine manipulator, dissection of the ureter in cases of 
distorted anatomy or willingness to place additional trocars) were noted as possible avenues to avoid injury. Such a discussion may point to areas of future investigation.

Our study is limited in its retrospective nature. It is a case-control study, which although helps to look for risks in relatively rare cases, such as lower urinary tract injury, may have selection bias. However, it does provide a multi-centered basis for researching hysterectomyassociated lower urinary tract injuries and provides a broader analysis of a relatively rare occurrence. Our approach highlights some of the potential sequelae of lower urinary tract injury, and reiterates the importance of continued research and education regarding ways in which surgeons can avoid such devastating complications.

\section{References}

1. Whiteman MK, Hillis SD, Jamieson DJ, et al. Inpatient hysterectomy surveillance in the United States, 2000-2004. Am J Obstet Gynecol. 2008; 198(1):34.e1-34.e7. [PubMed: 17981254]

2. Ibeanu OA, Chesson RR, Echols KT, Nieves M, Busangu F, Nolan TE. Urinary tract injury during hysterectomy based on universal cystoscopy. Obstet Gynecol. 2009; 113(1):6-10. [PubMed: 19104353]

3. Visco AG, Taber KH, Weidner AC, Barber MD, Myers ER. Cost-effectiveness of universal cystoscopy to identify ureteral injury at hysterectomy. Obstet Gynecol. 2001; 97(5 Pt 1):685-692. [PubMed: 11339916]

4. Symmonds RE. Ureteral injuries associated with gynecologic surge. Prevention and management. Clin Obstet Gynecol. 1976; 19:623-643. [PubMed: 954253]

5. Parpala-Sparman T, Paananen I, Santala M, Ohtonen P, Hellstrom P. Increasing numbers of ureteric injuries after the introduction of laparoscopic surgery. Scand J Urol Nephrol. 2008; 42:422-427. [PubMed: 18609278]

6. Harkki-Siren P, Sjoberg J, Tiitinen A. Urinary tract injuries after hysterectomy. Obstet Gynecol. 1998; 92:113-118. [PubMed: 9649105]

7. Vakili B, Chesson RR, Kyle BL, Shobeiri SA, Echols KT, Gist R, Zheng YT, Nolan TE. The incidence of urinary tract injury during hysterectomy: a prospective analysis based on universal cystoscopy. Am J Obstet Gynecol. 2005; 192(5):1599-1604. [PubMed: 15902164]

8. Jelovsek JE, Chiung C, Chen G, Roberts SL, Paraiso MF, Falcone T. Incidence of lower urinary tract injury at the time of total laparoscopic hysterectomy. JSLS. 2007; 11(4):422-427. [PubMed: 18237504]

9. Frankman EA, Wang L, Bunker CH, Lowder JL. Lower urinary tract injury in women in the United States, 1979-2006. Am J Obstet Gynecol. 2010; 202(5):495.e1-495.e5. [PubMed: 20223442]

10. Härkki-Siren P, Sjöberg J, Kurki T. Major complications of laparoscopy: a follow-up Finnish study. Obstet Gynecol. 1999; 94(1):94-98. [PubMed: 10389725]

11. Charlson ME, Pompei P, Ales KL, MacKenzie CR. A new method of classifying prognostic comorbidity in longitudinal studies: Development and validation. J Chron Dis. 1987; 40(5):373383. [PubMed: 3558716]

12. Nieboer TE, Johnson N, Lethaby A, Tavender E, Curr E, Garry R, van Voorst S, Mol BW, Kluivers KB. Surgical approach to hysterectomy for benign gynecological disease. Cochrane Database Syst Rev. 2009; 3:CD003677.

13. Janssen PF, Brolmann HAM, Huirne JAF. Causes and prevention of laparoscopic ureter injuries: an analysis of 31 cases during laparoscopic hysterectomy in the Netherlands. Surg Endosc. 2012; 27(3):946-956. [PubMed: 23052517] 


\section{Table 1}

Inclusion and exclusion criteria of ICD-9 and CPT codes for lower urinary tract injury in patients undergoing hysterectomy for benign reasons

\begin{tabular}{|c|c|}
\hline ICD-9 & CPT \\
\hline \multicolumn{2}{|l|}{ Inclusion Codes } \\
\hline 57.81 Suture of laceration of bladder & 51860 Cystorrhaphy, suture of bladder wound, injury or rupture; simple \\
\hline 57.82 Closure of cystotomy & 51865 Cystorrhaphy, suture of bladder wound, injury or rupture; complicated \\
\hline 57.89 Other repair of bladder & 51900 Closure of vesicovaginal fistula - abdominal approach \\
\hline 56.74 Ureteroneocystostomy & 57320 Closure of vesicovaginal fistula — vaginal approach \\
\hline 56.75 Transuretero-ureterostomy & 50930 Closure of ureterovisceral fistula \\
\hline 56.79 Other anastomosis or bypass of ureter & 57330 Closure of vesicovaginal fistula — transvesical and vaginal approach \\
\hline 56.82 Suture of laceration of ureter & 50700 Ureteroplasty \\
\hline 56.83 Closure of ureterostomy & 50760 Uretero-ureterostomy \\
\hline \multirow[t]{2}{*}{56.84 Closure of other fistula of ureter } & 50780 Ureteroneocystostomy \\
\hline & $\begin{array}{l}50947 \text { Ureteroneocystostomy with cystoscopy and ureteral stent placement } \\
\text { (laparoscopic) }\end{array}$ \\
\hline $\begin{array}{l}\text { 56.86 Removal of ligature from ureter } 56.89 \text { Other repair of } \\
\text { ureter: }\end{array}$ & $\begin{array}{l}50948 \text { Ureteroneocystostomy without cystoscopy and ureteral stent placement } \\
\text { (laparoscopic) }\end{array}$ \\
\hline \multicolumn{2}{|l|}{ 867.0 Urethral/bladder injury } \\
\hline \multicolumn{2}{|l|}{867.2 Ureteral injury } \\
\hline \multicolumn{2}{|l|}{57.84 Vesicovaginal fistula repair } \\
\hline \multicolumn{2}{|l|}{56.84 Ureterovaginal fistula repair } \\
\hline \multicolumn{2}{|l|}{ Exclusion codes } \\
\hline 68.6 Radical abdominal hysterectomy & $\begin{array}{l}58200 \text { TAH including partial vaginectomy, with para-aortic and pelvic lymph } \\
\text { node sampling with or without removal of tube/s, with or without removal of } \\
\text { ovary/ovaries. }\end{array}$ \\
\hline 68.61 Laparoscopic radical abdominal hysterectomy & $\begin{array}{l}58210 \text { Radical abdominal hysterectomy with para-aortic sampling and pelvic } \\
\text { lymphadenectomy with or without removal of tube/s, with or without removal of } \\
\text { ovary/ovaries. }\end{array}$ \\
\hline $\begin{array}{l}68.69 \text { Other and unspecified radical abdominal } \\
\text { hysterectomy }\end{array}$ & 58285 Vaginal hysterectomy (Schauta) \\
\hline 68.7 Radical vaginal hysterectomy & $\begin{array}{l}57240 \text { Anterior colporrhaphy, repair of cystocele with or without repair of } \\
\text { urethrocele }\end{array}$ \\
\hline 68.71 Laparoscopic radical vaginal hysterectomy & $\begin{array}{l}57250 \text { Posterior colporrhaphy, repair of rectocele with or without } \\
\text { perineorrhaphy }\end{array}$ \\
\hline 68.79 Other and unspecified radical vaginal hysterectomy & 57260 Combined anteroposterior colporrhaphy \\
\hline $70.50-70.55$ Repair of cystocele and rectocele & 57265 Combined anteroposterior colporrhaphy with enterocele repair \\
\hline \multirow[t]{2}{*}{$\begin{array}{l}\text { 70.77-70.79 Vaginal suspension and fixation, with or } \\
\text { without graft/prosthesis, including other repair }\end{array}$} & $\begin{array}{l}57267 \text { Insertion of mesh or other prosthesis for repair of pelvic floor defect, each } \\
\text { site (anterior, posterior compartment), vaginal approach }\end{array}$ \\
\hline & 57268 Repair of enterocele, vaginal approach \\
\hline \multirow{5}{*}{$\begin{array}{l}\text { 70.92-70.93 Other operations on cul-de sac with or without } \\
\text { graft/prosthesis }\end{array}$} & 57270 Repair of enterocele, abdominal approach \\
\hline & 57280 Colpopexy, abdominal approach \\
\hline & 57282 Colpopexy, vaginal; extra-peritoneal approach \\
\hline & $\begin{array}{l}57283 \text { Colpopexy, vaginal; intra-peritoneal approach (uterosacral, levator- } \\
\text { myorrhaphy) }\end{array}$ \\
\hline & $\begin{array}{l}57284 \text { Paravaginal defect repair (including repair of cystocele, if performed); } \\
\text { openabdominal approach }\end{array}$ \\
\hline
\end{tabular}

Int Urogynecol J. Author manuscript; available in PMC 2017 April 08. 


\begin{tabular}{ll}
\hline ICD-9 & CPT \\
\hline & 57285 Paravaginal defect repair (including repair of cystocele, if performed); \\
& vaginal approach \\
& 57288 Sling operation for stress Incontinence \\
& 56.85 Urethropexy \\
& 58240 Pelvic exenteration \\
\hline
\end{tabular}

Codes used for identification of patients; patients who had a hysterectomy for benign indications were identified by ICD-9 codes 68.3-68.9 and CPT codes 58150, 58541, 58542, 58543, 58544, 58180, 58260, 58262, 58550, 58552, 58553, 58554, 58290, and 58291 
Table 2

Demographic information

\begin{tabular}{llll} 
& Cases $(\mathbf{n = 1 3 5})$ & Controls $(\boldsymbol{n}=\mathbf{2 7 0})$ & $\boldsymbol{p}$ value \\
\hline Age (years) \pm SD & $45.2 \pm 7.6$ & $46.1 \pm 9.5$ & 0.33 \\
Ethnicity & Caucasian $(45 \%)$ & Caucasian $(49 \%)$ & 0.37 \\
& Hispanic $(40 \%)$ & Hispanic $(36 \%)$ & \\
& Asian $(13 \%)$ & Asian $(9 \%)$ & \\
& Other $(2 \%)$ & Other $(6 \%)$ & \\
Body mass index $\left(\mathrm{kg} / \mathrm{m}^{2}\right) \pm \mathrm{SD}$ & $27.9 \pm 11.6$ & $29.1 \pm 12.1$ & 0.36 \\
Uterine weight $(\mathrm{g}) \pm \mathrm{SD}$ & $459.4 \pm 719.6$ & $379.9 \pm 510.5$ & 0.21 \\
Medical comorbidities $(\%)$ & $39 \%$ & $36 \%$ & 0.51 \\
Injury detected after surgery $(\%)$ & $2 \%$ & $0 \%$ & 0.36 \\
Total abdominal hysterectomy $(\%)$ & $39 \%$ & $37 \%$ & 0.69 \\
Total vaginal hysterectomy $(\%)$ & $20 \%$ & $17 \%$ & 0.51 \\
Abdominal supracervical hysterectomy $(\%)$ & $6 \%$ & $8 \%$ & 0.49 \\
Laparoscopic-assisted vaginal hysterectomy & $10 \%$ & $7 \%$ & 0.2 \\
Total laparoscopic hysterectomy $(\%)$ & $10 \%$ & $10 \%$ & 0.98 \\
Laparoscopic-assisted supracervical & $10 \%$ & $14 \%$ & 0.37 \\
Robotic-assisted total laparoscopic & $5 \%$ & $7 \%$ & 0.18 \\
Bilateral salpingo-oophorectomy $(\%)$ & $37 \%$ & $40 \%$ & 0.6 \\
\hline
\end{tabular}

Int Urogynecol J. Author manuscript; available in PMC 2017 April 08. 
Table 3

Risk factors for lower urinary tract injury

\begin{tabular}{lll}
\hline Risk factor & Bladder injury OR (95\% CI) & Ureteral injury, OR (95\% CI) \\
\hline Prior cesarean section & $2.9(1.75-5)$ & NS \\
Total abdominal hysterectomy & $1.9(1.06-3.4)$ & $4.7(1.4-15.6)$ \\
Surgery by generalist OB/GYN & $2.4(1.2-5.2)$ & NS \\
Blood transfusion & NS & $33.4(7.3-153.2)$ \\
Laparoscopic-assisted vaginal hysterectomy & NS & $10.4(2.3-46.6)$ \\
Concurrent bowel injury & $8.9(5.6-17)$ & $21.1(1.6-167)$ \\
\hline
\end{tabular}

